\title{
Considerations on the Ethiopathogenesis of Algae from the Primary Form of BMD
}

\author{
BOGDAN IOAN COCULESCU1, GHEORGHE MANOLE², VALERIU-GABI DINCA ${ }^{2 *}$, ALEXANDRA-LIGIA DINCA ${ }^{3}$, \\ ELENA CLAUDIA COCULESCU 4 \\ 'Titu Maiorescu University Bucharest, Faculty of Medicine, 22 Dambovnicului Str., 031593, Bucharest, Romania \\ ${ }^{2}$ Colentina Hospital Bucharest, 19 Stefan Cel Mare, Bucharest, Romania \\ 3Medicover Hospital Bucharest, 24 Preciziei, Bucharest, Romania. \\ ${ }^{4}$ Carol Davila University Bucharest, Faculty of Dental Medicine, 8 Eroii Sanitari, 050474, Bucharest, Romania
}

\begin{abstract}
The study is motivated by the existence of a still controversial etiopathogen on Buming Mouth Syndrome. The objective of the study, which is carried out on a group of 103 sick of both sexes, presenting the Burning Mouth Disorder - the primary form, is to identify the prevalence of the disease and establish possible correlations with coexistence of age, gender and dyslipidemia as factors that can be considered as favoring the installation non-specific oral allergy. The conclusions of the research constitute an argument for admitting the hypothesis of the existence of a neuronal irrigation deficiency, manifested both at the conductive sensory fibers of the influx and, more preferably, at the sensory-sensorial cortex for pain and taste, or only at one of these levels. According to the hypothesis, neuronal suffering consists in a deficiency of energy production and use, induced by excessively local reactive oxygen species, through imigation, developed by the presence of arteriosclerosis.
\end{abstract}

Keywords: non-specific oral algal (ABN) / Buming Mouth Syndrome (BMS) / Buming Mouth Disorder(BMD), neuropathic pain, reactive oxygen species (ROS)

BMS also called dentistry or glossodynia / glossalgia, or after Anglo-Saxon Medical School BMD is a nonspecific algic syndrome characterized by dominance as a symptom of burning or stinging sensation in the entire mucous membrane of the mouth or only in some areas, frequently on the tongue.

Maladia has two forms (idiopathic and secondary); in the primary one there are no objective pathological signs. [1,2]. In this respect, defining the algae from BMS primary syndrome is based on the International Headache Society criteria: buming sensation inside the mouth/intraoral therapy for which no medical or dental reasons can be found. [3]

The International Association for the Study of Pain (IASP) identifies BMS as a form of neuropathic pain that is burning in the oral mucosa and is frequently bilateral. The disorder usually concerns the two previous thirds of the language and does not associate any visible sign of pathology at the mucosal level. BMS usually lasts for more than 6 months, with the possibility of recurrence [4].

Records of medical literature unanimously acknowledge that the presence of burning sensation at lingual / buccal level is characteristic of mild forms of illness, because in other forms it is associated with other symptoms, such as: paraesthesia, taste alteration, xerostomia, appetite suppression, etc. In severe forms, beyond the intensity of pain, personality or even psychic disorders such as anxiety, insomnia, irritability or depression coexist.

The prevalence of the syndrome is assessed differently, ranging from 0.6 to $15 \%[5,6]$. Its etiopathogens, which are still subject to controversy, are admitted to be multifactorial, or more often idiopathic $[4,6]$. Lauria G. et al. criticizes for the etiopathogenicity of the primary form of BMS the coexistence of a reduction in epithelial thin nerve fibers in the anterior $1 /$ 3 of the lateral parts of the tongue associated with axonal degeneration. According to the hypothesis, the presence of a low number of thin fibers would explain thermal hypo statics and increased thresholds for detecting tastes.
Following experimental studies, a similar conclusion is reached by Just T. et al. which admita reduction in sensitivity for pain and taste in the tongue $[7,8]$.

Albuquerque R.J.C. et al. analyzing brain activity by thermal stimulation of the trigeminal admit that patients with BMS syndrome-like syndrome have neuronal hypoactivity.

\section{Experimental part}

Material and method

The study group consists of 103 patients with $A B N$ syndrome, of which 61 (59\%) women and $42(41 \%)$ men (fig.1).

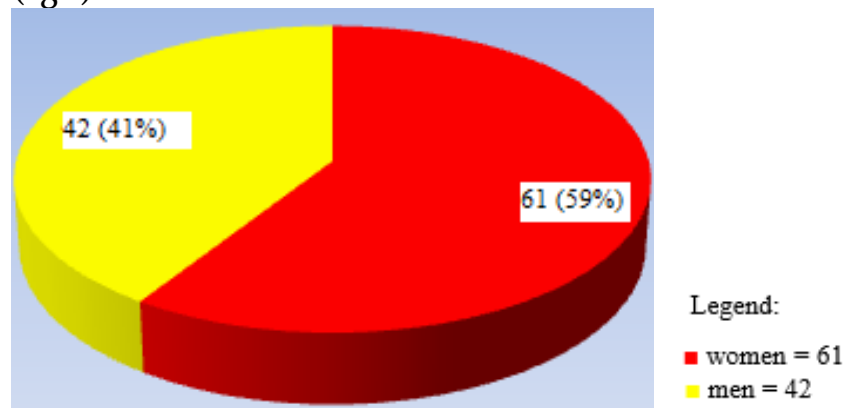

Fig. 1. Structure of the study group, in relation to the sex of the patients

Structured by age groups, the group comprised $70 \%$ of the patients over 50 years of age (table 1 ).

To form the batch, to be formed exclusively from patients with primary BMS, we were concerned with identifying the possible causes of the syndrome, not to co-opt patients with general disorders thought to be generating the secondary form $[7,10,11]$.

Also, knowing that saliva represents one of the external defense barriers and that oro- buccal lesions are factors favoring the development of superinfection, which metabolically modifies the salivary $\mathrm{pH}$, the patients were admitted to the study group only if the local exam and the 


\begin{tabular}{|c|c|c|c|c|c|c|c|c|}
\hline $\begin{array}{c}\text { Number } \\
\text { of cases }\end{array}$ & \multicolumn{3}{|c|}{ The sex of the sick } & \multicolumn{7}{c|}{ Age group in years } \\
\cline { 3 - 10 } & \multicolumn{2}{|c|}{} & $<40$ & $40-49$ & $50-59$ & $60-69$ & $70-79$ & $>80$ \\
\hline \multirow{4}{*}{\begin{tabular}{c} 
Women \\
\cline { 3 - 10 }
\end{tabular}} & $\begin{array}{c}\text { absolute number } \\
\text { \% of study lot }\end{array}$ & 59.1 & 8 & 9 & 14 & 16 & 11 & 3 \\
\cline { 2 - 10 } & $\begin{array}{c}\text { The average age of } \\
\text { the group }\end{array}$ & 57.9 & 31.4 & 43.3 & 54.3 & 63.31 & 74.48 & 80.66 \\
STRUCTURE OF THE STUDY GROUP \\
IN RELATION TO THE SEX AND AGE \\
OF THE PATIENTS
\end{tabular}

the results of the laboratory and paraclinical examinations required did not reveal the existence of local conditions such as caries, chronic gingivitis, periodontitis, etc.[12-17].

were:

a.assessing the prevalence of the primary form of BMS in relation to the sex and age of the patients;

b.highlighting the possible coexistence of BMS-type symptomatology, primary form with dyslipidemia. To achieve this goal, all patients were given the circulating values of: total cholesterol, $\mathrm{HDL}, \mathrm{LDL}$ and triglycerides, in order to identify the possible existing dyslipidemia.

\section{Results and discussions}

The distribution of the patients in the batch relative to the gender and the age group is summarized in the following table.

a.The average age of the batch was 57.31 years, sensitive to gender-based sublots (table 1).

b.In the investigated group, the ratio of BMS patients still in fertile and climax times revealed the predominance of the latter, being 2.5 (fig. 2).

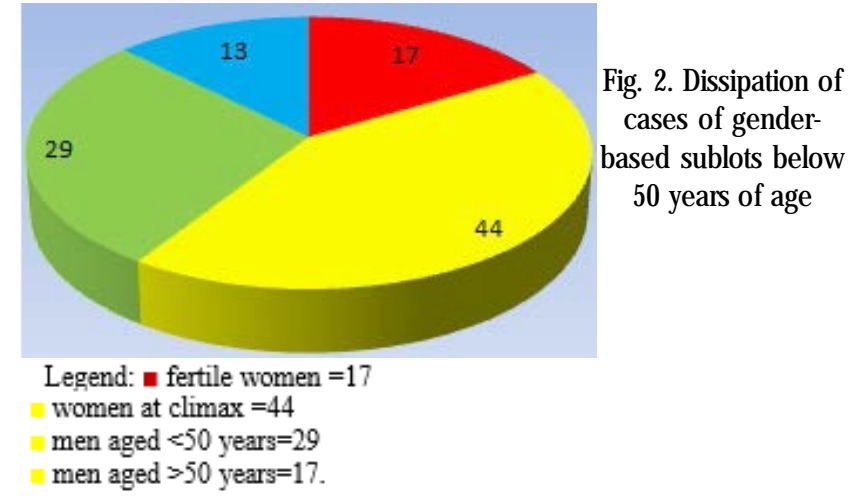

c.Even if the male sex does not describe the existence of andropause, In the studied group the number of those with BMS primary form less than 50 years was $4 \%$ lower compared to that of women of the same age groups (fig. .2).

women $/$ men $=17$ cases $/ 13$ cases $=16.43 \% / 12.63 \%$

d.The study of the composition of the batch relative to the age of the patients with oral algic syndrome - primary form shows that the number of those over 50 years, neglecting sex is $73=70.8 \%$, out of which 70 cases $=67.97 \%$ with age between $50-79$ years old (fig. 2). These data show that BMS develops predominantly in this age group, the percentage being:

$$
\begin{gathered}
\text { patients aged }<50 \text { years / patients with age }>50 \text { years } \\
=29.1 / 70.8
\end{gathered}
$$

This means that regardless of the sex of the patients, of 10 patients with non-specific oral algae, 7 are over 50 years of age, correlated with the presence of dyslipidemia. As a limit of the study, we did not investigate the prevalence of clinical signs of arteriosclerosis in patients in the study because we did not know that the results would lead us to such a conclusion.

e. The structure of the batch selected for the study confirms the records of the specialized medical literature that the female sex is a factor favoring the development of BMD syndrome. Thus, women accounted for almost $60 \%$ of the batch, a percentage superimposable to that of the literature, but with much wider women / men ratios up to $16 / 1$. The composition of the batch relative to sex and the age group, shown in table no.1, respectively figure 2 shows that the highest number of patients with BMS - primary form was for both sexes in the 50-79 age group, predominantly in females:

women $/$ men $=41$ cases (39.77\%) $/ 29$ cases $(28.20 \%)$.

f.The prevalence of cases of oral algal in this age group was explained by correlation with the incidence of dyslipidemia by the presence of the atherosclerosis process that begins to become manifest in most individuals since the sixth decade of life. The implication of atherosclerosis as an etiopathogenic factor allows us to formulate the hypothesis that the development of symptomatology in $B M D$ is the central neuronal lesions in the areas of integration of oral pain and taste or those of the constituent neurons of the sensory-sensory pathways of the sensitive message to cortex. In this latter hypothesis, the lesions would occur as a result of the atherosclerosis, including perinervascular vascular plexus, as it is known that this by diminishing the flow of organ can induce functional and trophic disorders, especially in some neuronal and axonal fluid.

In our view, the hypoxia of sensory neurons induced by arteriosclerosis would be responsible, in particular, for the development of functional disruptions in the management of the nervous influx through the components of the neuron, especially at the axon level. At this level, it is also possible to disturb the transmission of information at synapse level due to the existence of an energy shortage. This would be the consequence of a reduction in the synthesis of macroergic compounds / ATP as an expression of the supply of glucose, oxygen and electrolytes. However, the development of such a hypothesis in detail will be made by another communication.

g. In the case of patients with non-specific oral primary algae, our study data indicate that of 6 patients, 5 are at the menopause. We explain this through the biological status of climax, which on the female sex has a double consequence:

- induces the whole organism a true vegetative storm in varying degrees of clinical manifestation, with perturbation of perceptions including algo-thermal ones;

-develops hypoestrogenism, which pathogenically 
removes the hormonal factor that hinders their development of cardiovascular disease. Otherwise, the hormonal constellation of the woman at the menopause is similar to that of the man, which explains the development at a faster rate of atherosclerosis and its complications.[12,18-20].

$h$. In the case of the non-specific oral primary algae in patients less than 50 years of age, the prevalence of females predominates:

$\%$ women with BMD and age $<50$ years $/ \%$ men with BMD and age $<50$ years $=16.43 / 12.63$

The predominance of primary BMS in fertile women compared to the incidence of the same syndrome in men under 50 years of age has been explained by intervention as a factor favoring the constitutional ground determinism, disturbed by eventual endocrine disruptions or imbalance in cortical processes. We appreciate that if they existed they were minor as a manifestation, not allowing the clinical examination. We affirm this latter aspect, as some of the patients in the study at the time of the batch co-decision decision reported symptoms such as the presence of sleep disturbances, anxiety, depression but ignored because they were neither constant nor alarming. We mention that all the patients under study have undergone a psychological and psychiatric consultation.

Concerning the first possibility invoked, the existence of endocrine disorders, we mention that $27 \%$ of the fertile women with non-specific oral algus showed disturbances of the monthly duration or frequency of menstruation.

In asserting this last hypothesis for BMS patients with primary and under age 50 years comes the finding that male maladamia occurs at a relatively younger average age compared to women. This is explained by the more pronounced and quaspermanent exposure of the male patients to stress.

i.Relative to the various decades of life, in our study, the highest prevalence of BMS is:

-for women in the $60-69$ age group: $15.53 \%$, followed by age group $50-59$ years: $13.56 \%$ (table 1);

- and for men in the 50-69 age range, each decade showing the value of $10.68 \%$. These data show that for both age groups (50-59 and 60-69 years of age), BMS in primary form develops predominantly in females. The value of the multiplication coefficients being sensitively close, which allows us to admit that one can not establish a connection with the sex of the sick, whether it is apparent (table 3).

Table 3

VALUES OF PRIMARY BMD PREVALENCE VARIATION COEFFICIENTS, BY SEX, IN PATIENTS AGED 50-69 YEARS

\begin{tabular}{|c|c|}
\hline Age group & $\begin{array}{c}\text { The value of the } \\
\text { women } / \text { men ratio }\end{array}$ \\
\hline $50-59$ & 1.3 \\
\hline $60-69$ & 1.5 \\
\hline
\end{tabular}

The explanation for the almost similar evolution of BMS after age 50, irrespective of gender, has been explained by the already mentioned reasoning, that the menopause installation erases gender-related differences in the development of degenerative arterial disease.

a.Although the data of our study confirms the predilection of BMS development in primary form to female gender, comparing the average age of the batch that is 57.31 years, of which for women 57.9 years, and for men of 56.72 it allows to support that the onset of affection does not have a peculiarity related to sex (table 1).
The median age at which BMS was most commonly found in the group investigated by us is comparable to the data from other published studies.

\section{Conclusions}

Compared to other similar studies, our analysis is more common in the primary form of BMS in patients over the age of 60 , with prevalence of female gender: out of 5 patients, three are women. We do this by installing the climax that erases the particularities of the development of metabolism and the development of cardiovascular diseases between the two sexes.

Pathogenetically, we admit that the symptom of BMD in patients over 50 years of age is the expression of functional and / or trophic impairment of sensory-sensory reflex arc neurons, or those in sensory-sensory areas integrating oral pain and taste.

For primary BMD patients less than 50 years of age, we maintain that constitutional land is one of the responsible factors, especially in the presence of hormonal disturbances and / or the balance and mobility of cortical processes, whether minor or minor.

\section{References}

1.ARAVINDHAN R., VIDYALAKSHMI S., KUMAR S., SATHEESH C., MURALI BALASUBRAMANIUM A., SRINIVAS PRASAD V., Burning mouth syndrome: A review on its diagnostic and therapeutic approach, J. Pharm. Bioallied. Sci., 2014, Jul., 6, (Suppl 1), p.S21-S25;

2.MANOLE GH.,Fiziopatologie clinica generala, vol.II-Fiziopatologia organelor, Compania generala a Imprimeriilor. Ed. Coresi, Bucuresti, 2007;

3.*** INTERNATIONAL HEADACHE SOCIETY. Classification of BMS. Available from: http://ihs classification.org/en/ 02.../04_teil 3/13.18.05_f acialpain.html);

4.RENTON T., Burning mouth Syndrome., Rev. Pain,2011, dec., 5, (4), p.12-17;

5.ZAKREWSKA JM, HAMLYN PJ., Facial pain. In: Crombie IK, editor. Epidemiology of Pain. Seattle, WA: IASP Press; 1999. p.175-182;

6.ARAVINDHAN R., VIDYALAKSHMI S., KUMAR S.M., SATHEESH C., MURALI BALASUBRAMANIUM A., SRINIVAS PRASAD V. - Burning mouth syndrome: A review on its diagnostic and therapeutic approach, J. Pharm. Bioallied. Sci., 2014, Jul., 6, (Suppl 1), p.S21-S25);

7.SUN A., WU K.-M., WANG Y.-P., LIN H.-P., CHEN H.-M., CHIANG C.-P. Burning mouth syndrome: a review and update., J. Oral Path.\& Med., 2013, oct., 42, 9, p.649-655;

8.JUST T., STEINER S., PAU H.W. - Oral pain perception and taste in burning mouth syndrome. J. Oral Pathol. Med., 2010, 39, p.22-27;

9.ALBUQUERQUE R.J.C., LEEUW R., CARLSON C.R., OKESON J.P., MILLER C.S., ANDERSEN A.H. - Cerebral activation during thermal stimulation of patients who have burning mouth disorder: an fMRI study.,abstract, Rev. Pain, 2006, 122, p.223-234);

10.LOPEZ-J ORNET P., CAMACHO-ALONSO F., ANDUJAR-MATEOS P., SANCHEZ- SILES M., GOMEZ-GARCIA F. - Burning mouth syndrome: an update. Med Oral Patol Oral Cir Bucal 2010; 15, p.e562-e 568;

11.SCALA A., CHECCHI L., MONTEVECCHI M., MARINI I., GIAMBERARDINO M.A, Update on burning mouth syndrome: overview and patient management., Crit. Rev. Oral Biol. Med., 2003, 14, (4), p.275-291;

12.MANOLE GH., HARSOVESCU T., MOLDOVEANU E., BARA C. Consideratii asupra mecanismelor fiziopatologice ale hipoestrogenismului din postclimax in suferinta parodontala., Medicina Moderna, 2010, vol XVII, nr.3, p.142-152;

13.BALIGA SH., MUGLIKAR S., KALE R. - Salivary pH: A diagnostic biomarker. J. Indian Soc. Periodontol., 2013, jul.-aug., 17, (4), p.461-465; 14.MARSH P.D. - Microbial ecology of dental plaque and its significance in health and disease., Adv. Dent. Res., 1994, 8, p.263-270; 
15.MOORE W.E., MOORE L.H., RANNEY R.R., SMIBERT R.M., BURMEISTER J.A., SCHENKEIN H.A., The microflora of periodontal sites showing active destructive progression., J.Clin. Periodontol., 1991, 18, p.729-739;

16.MANDEL I.D. - The functions of saliva., J.Dent. Resp.1987, 66, p.623627;

17.BALWANT RAI, SIMMI KHARB, ANAND S.C.,Saliva as a Diagnostic Tool in Medical Science : a Review Study, Adv. in Med. Dent. Sci., 2008, 2, (1), p.9-12;
18.LAMEY P.J ., LEWIS M.A.- Oral medicine in practice: burning mouth syndrome., br. dent. J., 1989, 167, (6), p.197-200;

19.VINCENT D.E., MEYERS D.A. - Burning Mouth Syndrome: Background, Anatomy and Physiol, Medscape, iunie 2016 . Editor schief: Meyers D.A.; 20.CRISTESCU C., CAPITANESCU A., CRISTESCU V., CAPITANESCU C., NICULESCU C., STROE A., NICULESCU Z., MANOLE GH., Gingival mucosa, endothelial disfunction and menopause, Proceeding of the Romain Academy, serie B: Chemistry, life Sciences and Geosciences, 2010, vol.12, issue 2, p.133-147.

Manuscript received: 25.02 .2019 